\title{
A Jungly Feeling: the Atmospheric Design of Zoos
}

\author{
Michael Hauskeller \& Tom Rice
}

Designing Spaces and Atmospheres

"In general," one of us $(\mathrm{MH})$ wrote a quarter of a century ago, "atmosphere is that part of the object of perception that is not object but meaning. How the world is for us, that is, what sort of relation we have to it in any given moment and how we feel in it, we experience not representationally, but atmospherically." (Hauskeller 1995, 101) Atmospheres articulate the relation between the perceiver and the perceived (which is part of the perceiver's world).

When we design spaces, we also, whether or not that is our intention, design atmospheres. ${ }^{1}$ Atmospheres are, after all, everywhere that people are. Wherever people are, there cannot not be an atmosphere for them. We may not always be self-reflectively aware of it, but wherever we go we find ourself emotionally affected by our environment, not as a private, mental reaction caused by some of its physical features, but as a property of the space we inhabit. Normally, there is no perceived gap between cause and effect. In our experience, it is the world out there that is emotionally tinted: we just go with the flow and let ourself become attuned to the affective disposition of the environment. Atmospheres are objective moods, not in the sense that they exist independently of a perceiving subject, but in the sense that they are an integral, inseparable aspect of what is perceived.2 Moods, in turn, are evaluative states. No perceived object is ever

\footnotetext{
${ }^{1}$ Griffero $(2010,36)$ defines atmospheres as "spatialised feelings: that is to say, they are the specific emotional quality of a given 'lived space'." This does not mean that feelings exist first in a spaceless way, so that they can then be spatialised or not, and if they are, they are atmospheres. All lived spaces have an emotional quality, and there are no feelings that are not, in some way or another, "spatialised".

2 Hermann Schmitz once declared that "emotions are not more subjective than country roads, but only less fixable" (Schmitz 1969, 87). He is right, of course, but that does not mean that atmospheres are objective, just as country roads are. That is because one could just as well turn Schmitz's claim around and say, with equal justification, that country roads are not more objective than atmospheres, namely because 'country roads' do not exist as such, but
} 
completely value-neutral, because everything we perceive is part of our world, as we are part of its world, and everything that is part of our world and whose world we are part of, can be good or bad for us. It can be useful or harmful, can support our survival and our well-being, or hurt and destroy us. It can make our life better or worse, more or less worth living. We are existentially dependent on our environment, which, precisely for this reason, always poses an existential threat to us. We cannot afford to ignore the state of the world around us. The autonomous Cartesian or Kantian intelligible Self is nothing but a comforting fiction. For the likes of us, there is only embodied and extended being. Where we are is an essential part of what we are. Because of that, we perceive the world atmospherically.

Atmospheres indicate a presence. Every presence is ipso facto the presence of a power. The entirely powerless is never present. It does not exist for us. Perceiving the world atmospherically we acknowledge our own dependency and the existence of other powers around us. Atmospheres provide us with information about (or at any rate a rough indication of) the presumed nature of those powers, the collective name of which is 'reality'. ${ }^{3}$ Some atmospheres tell us what things are and how they can affect us. All atmospheres tell us that things are real (even if they are not). In that sense an atmosphere is a felt presence.

Reality matters. In order for us to take an interest in things, they need to be real to us. This does not mean that we need to think of them as real. In fact, we may even know that they are not real and still take an interest as long as they feel real to us. Creating an atmosphere is first and

only for us. The distinction between subjective and objective is a false dichotomy. Nothing is only objective, or only subjective. The fundamental datum is our finding ourself in a world. The subjective and the objective indicate opposite poles of one undivided experience. Things are more or less subjective, more or less objective, and the objective is actually the intersubjective (i.e. we call 'objective' what we all, or the vast majority of us, perceive in the same way). There is no object without a subject, and no subject without an object.

${ }^{3}$ Though for some, that name may be God. According to the Dutch philosopher of religion Gerardus van der Leeuw $(1933,140)$, the word God is first and foremost "the name for an experience of power". The sense of presence seems to be a main source of religious feeling, as also Williams James suggested in his Varieties of Religious Experience. "It is as if there were in the human consciousness a sense of reality, a feeling of objective presence, a perception of what we may call 'something there', more deep and more general than any of the special and particular 'senses' by which the current psychology supposes existent realities to be originally revealed." (James 1990, 59). Cf. also Otto (1917). 
foremost a way to make things feel real. Yet if atmospheres are everywhere that people are, it would appear that there is no need to create them in order to provide people with a sense of reality. We all have a sense of reality already. However, not all things are equally real to us at all times. By creating atmospheres around certain objects or ideas, we focus people's attention on them, increase their dominance in our phenomenological space, and make them more real to us than they might otherwise be. Yet things can also get too real. What the designer of atmospheric spaces needs to do is keep the right balance between the real-enough and the not-too-real.

\section{Atmospheric Soundscapes in Zoos}

The atmospheric design of zoos provides a good example of the need to balance the real-enough and the not-too-real. A modern zoo has many functions. It assembles and displays other-thanhuman animals (henceforth 'animals') in order to entertain and also to educate (though zoos also increasingly present themselves as organisations for conservation activities). The goals of entertainment and education are supported by the deliberate creation of atmospheres. This is necessary to attract visitors to the zoo and to build and maintain a reputation for providing interesting and exciting attractions. In order to stay competitive, they must create particular kinds of atmosphere, distinctive moods or feelings, which can be quite varied, ranging from cheerful excitement and a sense of adventure to respect and even awe (for instance through proximity to rare, precious, exotic and/or powerful animals). As zoos increasingly present themselves as places for conservation and education, they might also be sites for the production or reflection of Anthropocene anxieties (Whitehouse 2005), seeking to galvanise environmentally sensitive and responsible behaviours among zoo visitors through making them atmospherically cognisant and appreciative of what has been or might be lost. It is not always either possible or necessary, however, for a zoo to create a particular atmosphere that is clearly identifiable in terms of the 
moods that it conveys. Often it will be enough to create a space that is atmospheric in a more general sense. Not every atmosphere is an emotionally specific atmosphere (Rauh 2014). A specific atmosphere is an enhanced presence of a given object or complex idea, so that the mood it evokes is particular to that object or idea, very much like a proper name that marks out one thing (a person or a place) and one thing only.

Sounds can play an important part in the creation of atmosphere, though often they stay in the background, and it is in this sub- or semiconscious background that the atmosphere of a place is created. The second author of this chapter (TR) has a particular research interest in sound, and during a number of visits to zoos with his young children during 2017, was struck by the way these places became sonically atmospheric in both specific and non-specific ways. Having passed through the entrance of one zoo, he emerged into an open space where he was conscious of the co-presence of a variety of sounds: the murmur of adult human voices, excited cries and shrieks from children, calls from a nearby enclosure featuring exotic birds, the crackle of a walkie talkie worn by a member of staff, the whoosh of passing traffic, a short burst of a car alarm on a nearby road. There were no doubt other sonic presences too which contributed to the sonic environment (and hence to the perceived atmosphere) but which were not prominent enough for him to readily distinguish and identify. Perhaps because of the way these sounds issued from what, for him, was an unusual assemblage of sources with a wide range of associations, his own experience of this location was of a kind of atmospheric uncertainty, which left him unsure as to exactly how to engage with his immediate surroundings, and unsure of what attitude it was intended that he take forward into the zoo experience. At another zoo or 'wildlife park', this time in a rural location, he stopped to listen to what he later learned from a text panel was a lar gibbon (Hylobates lar) calling from high up in its enclosure. It was raining, and while 
he listened, drops pattered on the fabric of the umbrella he was holding and hissed on the concrete path. The space seemed charged, though in a way that he was unable to define. These places, at least in the lived moment, had an 'atmospheric feel', which is different from saying that they had the feel of a particular atmosphere. When we say that a place "has atmosphere" or "is atmospheric", then what we are saying is that it engages us affectively in non-specific ways, or in ways we find difficult to describe, whereas if a place produces a particular atmosphere then clearly it engages us affectively in ways we can identify and articulate. During a visit to a Safari Park, TR happened to walk through an area of enclosures just after feeding time when the animals were surprisingly active and vocal. Groups of visitors were responding enthusiastically: gesturing, exclaiming and commenting among themselves. Amidst all this human and nonhuman animation it was easy to reach for what seemed fitting adjectives. The atmosphere was lively and energetic. By contrast, at another Wildlife Park on an unusually cold and rainy day in summer, TR seemed to be one of the only visitors and very few animals were visible outside. An Emu (Dromaius novaehollandiae) in a small paddock pecked at the bottom of a bucket, making a hard thud with each contact and rattling the pellets of food that remained inside. Water dripped from its feathers. The atmosphere seemed heavy and sad. This is not to speak for the emu and its affective state, or to make any value-laden statement about its living conditions. There was not necessarily anything objectively or permanently 'heavy and sad' about the emu or the zoo in which it featured. Atmospheres are temporary and transient, they change easily, from one moment to the next. It seems likely, though, that the atmosphere was not what the Wildlife Park had desired to create. Atmospheres are at times elusive, resistant to attempts to design or construct them. They are unstable, and can be experienced in unpredictable and unintended ways. 


\section{Authenticity}

Zoos often use sound with the apparent aim of making exhibits more atmospheric. Many modern zoo exhibits are designed to evoke or give visitors the sense of being immersed in a particular kind of environment or ecosystem, and sound is added to enhance their effect. One exhibit visited by TR, for example, featured an array of nocturnal or crepuscular animals. As well as being dark inside, a track of jungle sounds with tropical birds and insects played for visitors as they moved through the space. In the viewing area of the humid and pungent pygmy hippo (Choeropsis liberiensis) exhibit nearby, TR noticed different jungle sounds issuing from speakers somewhere high up in the enclosure, out of plain sight. What seemed to be important in both these exhibits was that the atmosphere produced a sort of 'jungly feeling'. This was not necessarily the same atmosphere one would experience if one were actually in the place where the species of animals on display are found in the wild (and in the case of the first exhibit there is no location where that same combination of species are found together in the wild). So there is no need for absolute authenticity. In order to make them feel authentic the atmospheres created need not evoke what a place is (really) like, but merely what we think or imagine it is like. In fact, it is possible that real authenticity may undermine the experience that the zoo wishes to create. The atmosphere evoked should not be too real (as in exactly like the experience of being in a particular place), because the zoo experience is supposed to be a fun day out, while actually being in the jungle is probably a lot less fun. So we don't really want to feel in the zoo as if we were in the jungle. We want to have a surrogate feeling, a jungly feeling perhaps, but not a jungle feeling. We want to feel the wild, but that wild needs to be fit for our consumption.

At one zoo visited by TR, a 'crocodile swamp' exhibit (in this case Crocodylus porosus) included a recording of crocodiles with accompanying jungle sounds of thunder and some insect and/or frog sounds. This recording, (which is likely to be an assemblage of stock sounds, not of 
recordings of the animals that are actually in the zoo) was evidently used to make the place feel more like a real swamp. The atmosphere created, or that was intended to be created, was a paradigmatic 'swamp atmosphere'. Since few visitors will have ever been to a real swamp, however, the atmosphere created does not have to resemble the atmosphere that we are likely to experience in a swamp. What it has to resemble instead is the atmosphere that we think a swamp would generate. They are in fact tapping into cultural expectations of what a swamp should sound like, which might have little to do with an accurate representation of actual swamp soundscapes. What is more, visitors do not really want to feel exactly as if they were in a swamp surrounded by crocodiles, for obvious reasons. In a real swamp, out in the wild, there is no guarantee that you won't get eaten. Excitement, then, would quickly give way to fear or alarm.4 Zoos don't want their visitors to get afraid or alarmed, or only very slightly and in a very controlled and controllable manner. Many of the visitors are, after all, children. They need to feel safe. But they also want to feel excitement, the kind of excitement that comes from proximity to large, powerful wild animals. The intended atmosphere at the crocodile swamp thus needs to be highly ambivalent: it needs to convey an environment that is both potentially dangerous and entirely safe. For that, a hint of unreality is necessary, which can be introduced through the very artificiality of the created atmosphere's material constituents.

At another zoo visited by TR, hidden speakers are set at intervals in the hedge that you walk past as you approach the zoo entrance. They play out edited compilations of animal sounds, supposedly creating exactly the desired jungly feel, despite the fact, or perhaps precisely because

$4 \quad$ Naturally that also depends on the exact context of the swamp experience. MH recently went to Louisiana and on that occasion also took a boat tour through the swamps. The main attractions were the Mississippi alligators of which plenty can be seen in the water and on the banks. The tour guides offer them marshmallows on a stick to lure them to the boat and make them jump out of the water, thus providing a closer look and a more exciting spectacle for the tourists. Clearly, the alligators were used to that kind of thing and posed no real danger to the people on the boat. Accordingly, there was no cause for fear or alarm. On the other hand, the tour guide's stories and signs with stern warnings to keep one's hands in the boat made sure that the supposed fearsomeness of the alligators was not forgotten. Just as in zoos, there should not be too much fear, but not too little either (cf. Keul 2013, 947). Or in other words, we need to believe that the beast can kill us, but also that it won't. 
of it, that it would surely be impossible, or very rare, to hear elephants, monkeys and lions together or at least in such proximity. As indicated above, atmosphere is clearly more important than authenticity in the symbolic world of the zoo.5 But then zoos are also spaces where animals that would not normally be found close together live side by side. A zoo is a heterotopia in Foucault's sense (Foucault 1986), a place both real and unreal, where things stemming from different life worlds are precariously conjoined. So the sounds do to some extent reflect the same artificial universe as that created by the zoo. At the same time, the atmospheres created through the chosen heterotopian soundscapes are intended to conceal, at least to some extent, the actual reality of the place. The zoos the attempt to create a 'jungly feel' hides, or helps us to forget for a moment, the fact that the zoo is actually not the jungle and that the animals in it are not wild and free, but captive and semi-domesticated.

Part of a reptile exhibit at one of the zoos visited by TR featured a small bridge that arched over two pools. To one side of the bridge a waterfall tumbled down over a wall covered with plants into a small, deep pool containing some large fish and a Malaysian giant turtle (Orlitia borneensis). To the other side a female West African dwarf crocodile (Choeropsis liberiensis) with some of her offspring lay on the rocks at the edge of a wide, shallow pool that was also home to some small fish. TR could hear a chorus of chirping that he assumed to be another recording designed to produce a tropical atmosphere. However, the information board informed him that Trinidad Stream Frogs (Mannophryne trinitatis) could be seen around the waterfall and could also be heard chirping loudly like crickets. Try as he might, TR couldn't see the frogs, but their chirping was clear and rich. In combination with the falling water sound from the waterfall

5 It goes without saying that it is not only zoos where atmosphere has priority over authenticity. Rather, this is now the norm in all public places that also serve commercial interests. Jonathan Sterne, describing and analysing the function of music in the Mall of America (in Bloomington, Minnesota), points out how what he calls the "phantom objectivity of experience" has become a "pervasive social phenomenon". By organizing space in commercial settings and thus creating a fabricated environment designed to influence people's emotional attitudes and, as a consequence, behaviour, the outside social world is "folded into that which is most inside and private: the substance of affect and experience." (Sterne 1997, 46) 
the impression it created was quite beautiful. The zoo had clearly been successful here in creating what, for TR, was a pleasant and interesting atmosphere, but it was not necessarily an atmosphere that was jungle-like (in any case TR has never visited a jungle so would not be able to judge), nor can it conceivably have been at atmosphere at once like Malaysia, West Africa and Trinidad where the species in the exhibit could respectively be found in the wild (and again, having never visited these places TR is not qualified to make a judgment here). It was not even an atmosphere like a non-specific elsewhere. Instead the zoo had succeeded in creating a distinctive atmosphere that was qualitatively different from any other space in TR's experience. This atmosphere is that of the Reptile House. Zoos then, produce their own distinctive atmospheres, which are authentic in that they are authentically zoo-like.

\section{Directing People}

What one might tend to hear most on a busy day in a zoo are neither the animals nor even the recordings of jungly sounds, but the other people who are visiting the zoo. There is likely to be talking, but also sounds of fun and excitement: shouting and shrieking among the children who are perhaps the most important customer group for zoos. For that reason, the atmosphere can at times resemble that of other human-dominated leisure spaces such as the theme park, the funfair or the carnival.

There is a direct connection between the atmospheres we perceive and the way we act and behave. Zoo atmospheres are designed to afford satisfying and full experiences for visitors, but are also meant to make them act in certain predictable ways. Atmospheres direct people's behaviour. In a zoo setting this idea of direction is all-important. Given the comparatively recent repositioning of zoos as places of conservation and education it is imperative that zoos direct

people to think and feel in certain ways about the animals they see. Zoos want people to enjoy 
their visiting experience, but they also increasingly want them to value and care about the animals they see in the zoo and their conspecifics in the wild. Just as the music used in shopping malls contains instructions for the shoppers on how they should feel when using the products on display (cf. Sterne 1997), zoos use sound to influence our relation to the animals in them. Zoos want people to feel by turns excited, awestruck, concerned etc., and sound is one of the ways in which they convey this direction and orchestrate the visiting experience. For instance, one zoo

visited by TR had an underground viewing area with a huge glass window through which seals could be seen swimming underwater. Slow, ambient, aquatic-sounding music was being played in this space. There was no information on what the music was, who wrote it and when or with what intentions, but the music happened to be very effective in accompanying and enhancing the grace of a South American fur seal (Arctocephalus australis) that could be seen making long and seemingly effortless upside-down glides and tight acrobatic turns in the water. Other visitors were also gazing, some speaking but in hushed, almost whispered tones. The music had succeeded in producing an atmosphere that was quiet and respectful, that was a cue for but also afforded the expression of admiration and wonder.

\section{Atmospheres for Non-Human Animals}

Atmospheres in zoos are designed with their human recipients in mind. It is people, or more precisely, zoo visitors, that are the intended atmospheric audience. But the same soundscape that is used more or less successfully, for instance, to induce a feeling of being in a jungle, may have very different effects on those who work in or around that exhibit and who for that reason are constantly subjected to it. Through its constant repetition, the intended atmospheric effect of the recording may well become lost on keepers and other zoo employees, for instance. We might wonder, too, about the effect a soundtrack chosen to create the 'right' atmosphere for the zoo's 
visitors has on the animals in the enclosure. Perhaps crocodiles in an exhibit where sounds are used to create a 'swamp-like' effect experience those sounds very differently from the exhibit's human designers and visitors. Perhaps the noise worries them and should therefore be considered a potential welfare concern. Also, given that people may not all be affected by a soundscape in the same way, it is quite possible that individual animals in the zoo experience the artificial acoustic environments in which they are obliged to live in various, but equally atmospheric ways. It is beyond the scope of this chapter, but certainly important to consider, whether there are particular sound environments that do enable the production of atmospheres in which zoo animals (at the level of the individual as well as the species) feel comfortable.

Whether non-human animals actually perceive atmospheres is of course an open question, one that, curiously, never really comes up in the philosophical literature, possibly because the study of atmospheres, as with the current chapter, heavily relies on the first-person perspective, with which non-human animals cannot provide us. So it is difficult to know for sure. But if they do, we cannot necessarily expect those atmospheres to be similar to the ones we perceive in the same situation, simply because how we perceive the world, how it affects us, depends very much on the way we relate to that world: our human needs and desires, hopes and fears, likes and dislikes. By the same token, however, we should fully expect, from what we know about atmospheres, that non-human animals also experience them, because atmospheres are there for us not insofar as we are thinking beings, but insofar as we are animals: embodied, world-inhabiting beings in a world that can harm and destroy us, or sustain and support us. It is true that in our own case what we know and believe, certain conceptual associations as well as emotional connotations and phenomenal characters all co-determine the atmosphere we experience. However, atmospheres are not a product of abstract thinking. They affect us more viscerally because they are tied to our creaturely needs and vulnerabilities, expressing our basic relation to the world, so that if anything 
it should be expected that animals are just as subject to atmospheric perception as humans, and likely even more so. We should therefore assume that there are atmospheres within enclosures or within species-specific and perhaps even inter-species groups at the zoo. A troop of Hamadryus baboons (Papio hamadryas) in one enclosure TR visited, for instance, may well be able to wake up in the morning and intuit the general mood of their group, picking up on the atmosphere which might be one of tension, hostility, calm, euphoria or many other things, depending on group dynamics, but not reducible to it.

\section{Conclusion}

Zoos are very much concerned with the production of atmospheres, and sound is centrally involved in this process. By producing atmospheres, they build, shape, and regulate the relations between the people (the visitors, but also those working there) and the space they temporarily or routinely inhabit. Since that space is a zoo space, i.e. one that is filled with animals, it is inevitable that the resulting atmospheres also shape and regulate our relation to those animals (as well as, presumably, their relation to us). As we have seen, zoos are atmospherically complex, and they face continual challenges as they try to design and maintain atmospheres in line with simultaneous continuity and change in their declared purpose as sites for entertainment, education and increasingly, conservation and the encouragement of environmentally responsible behaviour. Perhaps the key atmospheric challenge for zoos is to reconcile visitors' desire to observe and experience forms of natural and ecological otherness (often simulacra of geographically distant environments, though these should not be so real and convincing that they scare visitors off) with the realities of managing and displaying closely controlled animal populations. 
Above we raised the question as to whether animals might experience atmospheres, and whether atmospheres might conceivably be designed with their wellbeing in mind. This kind of 'atmospheric thinking' (which has clear ethical implications) could represent an interesting future direction for zoos. What atmospheres should we want at zoos? What atmospheres might be best for all concerned, animal residents as well as visitors and keepers? 'Thinking atmospherically' might also present a means of stimulating reflection: challenging zoos and their visitors to think about what kinds of atmosphere they really want, and are happy to be complicit in producing.

\section{Cited Works:}

Foucault, Michel (1986): “Of Other Spaces”, Diacritics 16 (1): 22-27.

Griffero, Tonino (2008): Atmospheres: Aesthetics of Emotional Spaces, Farnham: Ashgate.

Hauskeller, Michael (1995): Atmosphären erleben, Berlin: Akademie Verlag.

James, William (1990): Varieties of Religious Experience, New York: Vintage Books.

Keul, Adam (2013): "Embodied encounters between humans and gators", Social \& Cultural Geography 14 (8): 930-953.

Otto, Rudolf (1917): Das Heilige, 23th-25 $5^{\text {th }}$ ed. Munich 1947.

Rauh, Andreas (2012): Die besondere Atmosphäre. Ästhetische Feldforschungen, BielefeldÖ transcript Verlag.

Schmitz, Hermann (1969): System der Philosophie III.2: Der Gefühlsraum, Bonn: Bouvier.

Sterne, Jonathan (1997): "Sounds like the Mall of America: Programmed Music and the 
Architectonics of Commercial Space", Ethnomusicology 41 (1): 22-50.

Van der Leeuw, Gerardus (1933): Phänomenologie der Religion, Tübingen.

Whitehouse, A. 2015. "Listening to Birds in the Anthropocene: the anxious semiotics of sound in a human-dominated world", Environmental Humanities 6: 53-71. 